\title{
A Critical Reflection on the Involvement of 'Experts by Experience' in Inspections
}

\section{Peter Scourfield}

Peter Scourfield qualified as a social worker in 1984. Since then, he has worked in various settings, latterly in an Older Person's team. Since 2003, he has worked full time as lecturer at Anglia Ruskin University. His writing and research interests are mainly focused on the adult social care system, with a particular interest in older people's services.

Correspondence to:

Peter Scourfield,

Faculty of Health and Social Care,

Anglia Ruskin University,

East Road,

Cambridge

CB1 1PT

UK.

E-mail: peter.scourfield@anglia.ac.uk

\begin{abstract}
Recent research conducted in the UK for the Commission for Social Care Inspection (CSCl) suggested that there was no evidence to indicate that the involvement of service users and lay assessors in service inspections improved the quality of inspections. However, recently, $\mathrm{CSCl}$ has initiated a project to involve 'experts by experience' in their service inspections. Here, the term 'expert by experience' has been adopted to describe users of social care services. However, the appropriateness of this usage has not been without some challenge and various conceptual difficulties have been raised in how the term is used. Reflecting on reports published by $\mathrm{CSCl}$, this paper considers whether the choice of the word 'expert' in this context is really appropriate and also whether, although well intentioned, the involvement of 'experts by experience' is too confused in its rationale to actually empower the people using the services being inspected. The paper concludes by suggesting that the current inspection body - the Care Quality Commission - would do well to review both the terminological and conceptual confusion in respect of this practice.
\end{abstract}

Keywords: care home inspections, critical reflection, lay assessors, service users

\section{Introduction}

Recent research conducted in the UK for the Commission for Social Care Inspection (CSCI) suggested that there was no evidence to indicate that the involvement of service users and lay assessors in service inspections improved the quality of an inspection (Simmill-Binning et al., 2007). More recently, McLaughlin (2008) has highlighted various conceptual difficulties with the term 'expert by experience'. Taking these two recently published views into consideration, the initiative by $\mathrm{CSCl}$ (now subsumed under the Care Quality Commission) to involve 'experts by experience' in their inspections created a desire to learn more about how the initiative was working in practice.

On closer examination, the summaries of the CSCl (2007a; 2007b) evaluation reports appear, unfortunately, to raise more questions than they answer. It has led to a considerable degree of puzzlement, both in terms of how the word 'expert' has come to be used and about the justification provided for including 'experts by experience' in service inspections. Drawing on the findings summarised in the $\mathrm{CSCl}$ reports, this paper reflects on what it means to be an expert and whether the choice of the word 'expert' in this context is particularly appropriate. However, accepting that this is the current terminology, the discussion then turns to whether involving 'experts by experience' is the most appropriate method of ensuring that the perspectives of people using services are effectively taken into account in inspections. 


\section{Who is an expert? Not all experts need be professionals}

Expert-a person who is very knowledgeable about or skilful in a particular area (Shorter Oxford Dictionary of English, 2005, p. 610).

In the popular imagination, an expert is someone who usually acquires their expertise, and therefore 'earns' their expert status, through a process of learning rather than simply having the status ascribed to them. There are, undoubtedly, different ways of acquiring expert status-some more restricted and regulated than others. To some extent, it depends on in what area or 'domain' of skill and knowledge the expertise is being claimed. In many domains, the power to control who can claim to be an expert is exercised by the professions (Johnson, 1972). Traditionally, the acquisition of professional expertise begins with the successful completion of training and education programmes approved by the profession itselfcommonly, but not exclusively, in the higher education system. This is then developed by time spent in practice, usually learning from more senior professionals.

White and Taket (1994) explicate a commonly held view of how professions emerged and established their claims to expertise. It is seen as a historically situated process whereby professional 'disciplines' exercise power and control over domains of knowledge and therefore claim expertise as their own. They state that:

Following the project of Foucault, others have shown that the concept of expertise is not a natural one, in that it only erupted in certain fields at particular points in history, and its form is unstable, hence open to transformation. In their studies, the expert is a modern figure, emerging in the 19th Century, a creation of liberal discourses, who plays an integral part in governing and controlling individuals and populations at a distance, through the establishment of a network of experts. Expertise first appeared alongside the emergence of the liberal professions of medicine and law, where knowledge on sickness, health, sanitation, rights, and so on was not the province of government, but of experts who play their role as part of a network of power which saturates the social field rather than being enforced from above. In modern society there exist experts on all aspects of life who take individuals as objects of knowledge (White and Taket, 1994, p. 735).

White and Taket argue that, in the postmodern society, the privileged position of the expert is questioned. They argue that:

....it is a mistake to accept the expert as having the final word as to the meaning of the client's problems (White and Taket, 1994, p. 735).

Certainly, professionals are the 'agent[s] of expertise discourses' (Fischer, 2003, p. 40) and thus continue to exercise power and control in social life. However, one does not have to be a postmodernist to notice that the knowledge claims and authority of professional and other experts in contemporary society are now routinely challenged. Therefore, it is helpful to understand changing constructions of both the professions and experts in their historical context. As Higgs and Titchen (2001) observe:

In reflecting on the evolution of the professions and the context in which this evolution has occurred, it is evident that the ways in which society and the professions have viewed and interpreted expertise over time are deeply embedded in the ways the professions are conceptualized, practised and managed. This is the historicism principle in action. We cannot view expertise as a single, unchanging or universal concept or model. Instead, we ask the questions:

- What does a society expect of those on whom it bestows the label 'expert'?

- How do members of a particular profession define and judge their experts?

- What are the desired goals or characteristics to which each professional in a given context should aspire in the journey towards expertise? (Higgs and Titchen, 2001, p. 63).

These questions, the first in particular, are worth bearing in mind as this discussion progresses. The adoption of the term 'expert' in the context of 'experts by experience' can be understood as a self-conscious and deliberate attempt to confront the power of the professions and democratise 'expertise' in the domain of health and social care. It is used in order to equalise power differentials and to suggest that expertise by experience is every bit 
as valid as professional expertise. However, the deployment of the language of the 'expert' is a risky strategy. It inevitably places those so described under scrutiny-even suspicionabout quite what their 'expert' credentials are. This is because in the twenty-first century, expert knowledge, and experts in general, occupy, at best, an ambiguous position. As modern societies face more and more complex problems, the demand for expert opinion both to provide solutions and to alleviate uncertainty grows. However, experts-in all domains-find their privileged claims to knowledge and authority increasingly challenged (Beck, 1992). The dramatic expansion of the internet since the 1990s means we now live in a world saturated with 'knowledge'. People have become accustomed to not only checking, but also challenging what experts do and say. These days, experts, in any field, must now be prepared to be judged. Therefore, whilst expert status carries with it responsibility, it certainly does not automatically carry with it unqualified respect or deference. Appending 'by experience' does not diminish the prospect of scrutiny of credentials; if anything, it increases it. To face the judgement of others about the legitimacy of one's expertise gained by experience might be empowering to some but it might equally be devastating to others. Rightly or wrongly, the decline in trust in experts has been accompanied by a willingness to go a step further and knock experts down.

\section{The context of service user involvement}

The term 'experts by experience' has been adopted in various contexts in UK social work and social care in recent years-for example, in social work education (Preston-Shoot, 2007). It is not a term that is used consistently. In some cases, it is used interchangeably with 'service user' and, in others, it refers to a particular type of service user. Sometimes, it is a way that service users choose to define themselves. The emergence of the term needs to be understood in the broader context of 'service-user involvement', the literature on which is both huge and diverse. Various commentators have identified 'democratic' and 'consumerist' models of involvement, each distinguished by the degree of real power that shifts to the service user (Beresford and Campbell, 1994). It has also become customary to differentiate approaches to involvement that are either 'top-down' or 'bottom-up'-that is to say, orientations that reflect managerialist/quality assurance strategies or grass roots struggles for rights and recognition (see, e.g. Seden, 2008). It is not the intention, here, to analyse or comment on this literature in any great depth, but rather to place the discussion in context by positing that, at bottom, these various, interwoven agendas have established the principle that, at some level and in some way, service users should have more of a say in the decisionmaking processes that affect them. However, given the various ambitions, tensions and complexities involved, not surprisingly, many challenges still remain in this respect (Brown, 2000; Carr, 2004). That said, the discursive and policy environment is such that those responsible for service provision, whether this be in terms of commissioning, regulation or direct provision, are left in no doubt that they must involve their 'clients/patients/serviceusers/customers' at some point. The use of 'experts by experience' therefore needs to be understood in this broader context.

\section{Changing inspection regimes}

Policy and practice concerning the inspection and regulation of care services have a relatively brief history. However, as Martin (2005) observes:

Because the policy agenda has developed so rapidly, inspection frameworks have been in an almost constant state of change over the last seven years. Performance measures and inspection criteria have been constantly tinkered with (Martin, 2005, p. 501).

Since the introduction of community care in 1990s, there has been a constant 'turnover' of regulatory inspectorates (Davis and Martin, 2008). Indeed, during the writing of this paper, the chief inspection body responsible for adult social care in England, the Commission for Social Care Inspection, transmuted into the Care Quality Commission in April 2009.

Wright (2005) explains how the Citizens Charter of the 1990s led to the introduction of 'lay assessors' in residential care service inspections. These were ordinary members of the public provided with some basic training. Mainly, their role was to observe and talk with both 
staff and residents and provide feedback for inspection reports. Wright cites Department of Health guidance, which states that lay assessors:

...can reinforce the importance of common-sense observation in inspection and make a distinct contribution from the perspective of users, families and the wider community (Department of Health, 1994, para. 11).

Wright's study into the use of lay assessors in care home inspections showed that those involved-inspectors, managers and care staff-were mainly positive. However, some residents were puzzled, not only about the precise role of the lay assessor, but also by what the point of the inspection was. Nevertheless, Wright concluded:

At the very least, lay assessors can provide a mechanism for gauging resident satisfaction. The lay assessor system originally established was far from perfect and more could have been done to recruit people representative of service users (Wright, 2005, p. 1105).

In recent years, the concept of the 'lay assessor' had been dropped by both $\mathrm{CSCl}$ and its successor, the Care Quality Commission, as far as social care service inspections are concerned. Subsequently, when referring to the involvement of non-professional inspectors, $\mathrm{CSCI} / \mathrm{CQC}$ now talk about the use of 'experts by experience'.

\section{Experts by experience}

What exactly distinguishes an 'expert by experience' from a 'lay assessor' has not been officially explained. Although, for that matter, what constitutes being an 'expert by experience' is open to different interpretations. According to the Commission for Social Care Inspection (CSCl):

The phrase 'experts by experience' is used to describe people whose knowledge about social care services comes directly from using social care services. In CSCI we use the term experts by experience to describe people who use services, who have chosen to become more closely involved with the organisation developing their skills, knowledge and expertise (CSCI, 2009, p. 2).

According to guidance issued by $\mathrm{CSCl}$ to inspectors to help them understand how and when to use 'experts by experience':

- An 'expert by experience' is a person who, because of their shared experience of using services, and/or ways of communicating, visits a service with an inspector to help them get a picture of what it is like to live in or use the service.

- Experts by experience do not need to have experienced an identical service. What matters is that they know what it is like to need a service $(\mathrm{CSCl}, 2007 \mathrm{c})$.

From these explanations, the experience of directly using any form of service qualifies one as an expert for the purposes of inspections. As the last point makes clear, it need not be the same service.

According to the Care Quality Commission, which retained CSCl's concept of 'experts by experience' in inspections, 'experts by experience' are:

- people who are using services now or have done in the past

- people who need services but haven't been offered them

- people who need services but haven't been offered any that are appropriate

- people living with or caring for a person who uses services (Care Quality Commission, 2009) 
Here, we see a broader definition being adopted. One need no longer be a direct user of services (current or past) to qualify as an expert. Expertise can be gained through the experience of needing services and not being offered them, by being offered inappropriate services or by living or caring for a service user. These definitions inevitably raise questions about both the degree and the nature of the 'expertise' assumed to be gained.

The labelling and re-labelling of users of social care and social work formed the topic of a recent article by McLaughlin (2008). Not unreasonably, he interrogates the more recent label 'expert by experience', asking:

How are we to recognize who is not an 'expert by experience'? Who decides, and what criteria do they use? The use of the term 'experts by experience' eschews such debate by including both experts and experience in the title, deflecting attention from either term. In terms of experience, we are all aware of individuals who do not learn from experience and five years' experience may only mean the same year, five times...It is therefore difficult to see who cannot be an 'expert by experience'. It also provides no way of deciding how different experiences may be evaluated or compared (McLaughlin, 2008, p. 13).

McLaughlin's reflections lead him to conclude that:

This leaves the notion of 'experts by experience' in a weak position, as it is unable to identify distinct populations, or distinguish between individuals who use services. It is also debateable whether social workers or social care practitioners could also claim to be 'experts by experience' (McLaughlin, 2008, p. 13).

The status of 'expert' is said to be derived from the experience of using social care services and, notwithstanding McLaughlin's valid set of objections, this justification at least has some reasoning behind it. Put simply, the individual possesses knowledge about something because they have experienced it. One might surmise, again pace McLaughlin, that the more one uses a service, the more one might be considered an expert on it. The fact that someone has acquired unique insights gained from experience is the basis for their expertise. Arguably, this is the one thing that professionals, however highly trained, can never truly know. That is what the suffix 'by experience' denotes.

Nevertheless, the use of the word 'expert' in 'expert by experience' is fraught with difficulty. This is partly because it is unclear whether other service users or the public at large would be prepared to accept this expertise in the same way as they would, rightly or wrongly, the expertise of a professional. It is also partly to do, as McLaughlin says, with the criteria not being made clear. The term 'expert by experience', therefore, seems to fulfil a symbolic function, self-consciously conferring equal status on both service user and professional. However, whether 'expert' is the most appropriate term to fulfil this function is debatable. When used indiscriminately and without qualification, it is hard not to be troubled by patronising undertones-albeit inadvertent-in the way the word 'expert' is used.

\section{The use of 'experts by experience' in CSCl inspections}

$\mathrm{CSCl}$ estimated that 'experts by experience' would be used in approximately 4 per cent of all inspections for older people and 5 per cent for other services (CSCl, 2007c, p. 2). 'Experts by experience' are recruited, supported and trained and paid for by different support organisations, such as NCILs, Age Concern and Help the Aged. The role that 'experts by experience' are expected to perform is explained thus:

The three tasks that an expert by experience can do are:

- Talk to people who use services, staff and management

- Observe daily life in the service and the interaction between staff and people who use services

- $\quad$ Look around the premises (CSCl, 2007c, p. 3). 
This role, therefore, bears a strong resemblance to that of a lay assessor whose value was thought to reside in their having more time to talk to service users and being able to bring a well meaning 'common sense' perspective (Wright, 2005). As with lay assessors, the 'experts by experience' are seen by the professional inspectors as an additional means by which inspection data can be collected. CSCI explain:

We use a targeted approach to our inspection methodologies. Experts by experience are one option of a range of communication tools and methodologies that help us relate better to people who use services (CSCI, 2007c, p.1).

We use information from experts by experience to help us triangulate evidence and verify any issues (CSCl, 2007c, p. 1).

The language used, for example, 'a range of communication tools and methodologies', 'triangulate evidence' and 'verify any issues', suggests a high degree of scientific rigour occurs in such inspections. However, it is not explained why, if the role is so critical for methodological soundness, 'experts by experience' will only be used in 4-5 per cent of inspections. The criteria for their inclusion in some inspections and not others are not explained.

\section{CSCl evaluations}

CSCl's own evaluations of the use of 'experts by experience' in inspections provided strong endorsement for their inclusion. Two summaries of the evaluation reports are available on the $\mathrm{CSCl}$ website. One focuses on care home inspections (CSCl, 2007a) and the other on domiciliary care inspections ( $\mathrm{CSCl}, 2007 b)$. The message of the care home report is unequivocally positive:

This is one of the most positive things that $\mathrm{CSCl}$ have introduced in a long time. The insight that the experts have provided has been invaluable, and they have been extremely well received by care homes (Inspector) (CSCl, 2007a, p. 1).

The report goes on to explain:

Experts by experience were able to pick up on and note details, such as care practices, accessibility within the home, interaction and non-verbal communication between staff and people who use the services. Using different tools, such as picture cards, easy questions with pictures and their own observation techniques proved helpful. This added evidence to the inspection reporting process ( $\mathrm{CSCl}, 2007$ a, p. 1).

The extracts clearly show that the initiative generated examples of good partnership working between the inspectors and the 'experts by experience, and one would not want to disparage these achievements. However, even these extracts raise difficult questions of both whether and how the knowledge gained from one individual's experience in a specific situation can be transferred to another. One can see, for example, how the experience of an impairment that is shared by others might well equip somebody with the necessary insights to comment on 'accessibility within the home'. However, the ability to comment insightfully on 'interaction and non-verbal communication between staff and people who use the services' is far more complex an issue. It is not clear how this is made any easier for the 'expert by experience' than for the inspector. Presumably, one would need to know both the staff and the people who use the services quite well in order to be able to do this 'insightfully'.

The report does highlight what it refers to as 'minor concerns'. Some of these add to the confusion about the nature of the 'expertise' brought by 'experts by experience' to the inspection process-and how it is used. The report states:

Experts by experience were also good role models for people who used the service. Providers/managers were also open and willing to learn and receive feedback. Minor concerns included lack of publicity about the project, a mixed response from providers on having an expert by experience on the visit and the individual skills of the experts by experience ( $\mathrm{CSCl}$, 2007a, p. 2). 
It is not made clear how 'experts by experience' were good role models for people who used the service. In any event, role-modelling is not usually considered to be in the remit of service inspectors. If role-modelling is considered a key function, then perhaps this aspect of the inspection agenda should be made more explicit. The use of the term 'expert' in ways that both amend and extend its more traditional meanings has emerged in other public service contexts in recent years in the UK. For example, 'expert patients' (Wilson, 2001) and 'expert carers' (SPRU, 2009) have emerged in discourses on health and social care. This phenomenon provides interesting insights into developments in welfare governance in the UK. The label 'expert', when used in these contexts, is increasingly becoming a 'technology' or discursive means by which specific welfare subject positions are delineated. In this respect, to be designated an 'expert' does have a role-modelling function. It informs us how we should be, both as citizens and people-active, responsible and self-managing (Newman, 2005; Newman et al., 2008; Powell, 2008). However, whether people need to be provided with 'expert' role models by those inspecting the services they use is a moot point. Arguably, it would be more appropriate for the staff to be provided with such role models-if that is considered a function of inspections.

One of the minor concerns noted was 'the individual skills of the experts by experience'. In their definition, $\mathrm{CSCl}$ state that 'experts by experience' can develop 'their skills, knowledge and expertise' by becoming more closely involved with the organisation (CSCl, 2009, p. 2). This might suggest that the 'expert by experience' undergoes a form of quasiprofessionalisation. It reflects a degree of confusion about what 'experts by experience' are supposed to bring to inspections. Arguably, it places them in a form of categorical limbobeing somewhere between a service user who is authoritative about their own experiences and a lay assessor who has been given some on-the-job training on how to communicate with service users and what to look out for. However, the critical point to be made about 'experts by experience' is that their knowledge and expertise are unique to them. After all, that is what they are valued for. It is unclear how their particular experiential expertise will be enhanced by seeing things more from the perspective of the organisation. Becoming thus co-opted does not add to the quality that makes them an expert; if anything, it detracts from it (Selznick, 1949).

The following quotation from an inspector is also problematic:

I feel that the expert had a clear understanding and awareness of how to obtain the required information to contribute to the inspection process. Service users felt relaxed talking to him. He was able to relate to people very well. He was able to observe non-verbal communication that validated his and my thoughts. The registered manager was very pleased that an expert by experience was at the inspection (Inspector) (CSCl, 2007a, p. 2).

The statement from the above inspector that 'he [the expert] was able to observe non-verbal communication that validated his and my thoughts' is expressed ambiguously. However, it could be read as if the perceived value of the 'expert by experience' lies in being able to validate an inspector's thoughts. This may not be intended but, unfortunately, that is the impression created. This concern is hardly dispelled by the following claim:

Our improved credibility-putting people at the heart of what we do, the impartiality and independence of experts by experience, the additional evidence which confirms the inspectors [sic] opinions and which makes our findings more balanced (CSCI, 2007a, p. 2).

Surely, the benefit of an independent person (whoever this might be) at an inspection is that, being independent, they might confirm the inspector's opinions, but equally, they might add to, qualify or even challenge those opinions. These quotations raise awkward questions about the power relations between the two types of 'expert'.

The report on care homes inspections makes it clear that, whilst being very positive about how the project started, $\mathrm{CSCl}$ and their collaborators were aware that several issues needed to be sorted out. However, the issues identified are more of a practical nature. Some of the more problematic conceptual issues are not discussed. 
To conclude, it is worth highlighting another troubling feature of the care homes report. Nine quotations are used from participants: five from inspectors, three from 'experts by experience' and one from a provider. Interestingly, there is no record of what a service user using one of the inspected services thought about the experience of having 'experts by experience' involved. This conveys another element of confusion about what it means to involve service users in inspections. The focus appears to be more about meeting the needs of the 'experts by experience' (i.e. the inspectors) than on those of the people using the services inspected, which suggests a degree of unacknowledged goal displacement.

The evaluation report of the involvement of 'experts by experience' in domiciliary care inspections (CSCl, 2007b) is more equivocal about the success of the pilot project, referring to a 'mixed reaction' to the involvement of experts by experience (CSCl, 2007b, p. 1). Several practical and organisational issues are identified as needing to be addressed. It was reported that many inspectors were not convinced that the use of 'experts by experience' was useful in undertaking home visits, for various reasons. They were given the task of conducting telephone interviews instead. However, despite these and other issues, the overall rationale for involvement remained unchallenged.

In line with the care home evaluation, $\mathrm{CSCl}$ report that in domiciliary care inspections:

The involvement of experts by experience has improved our credibility, enabled us to meet our principles and given the inspection process impartiality and independence (CSCI, 2007 b, p. 2).

'Credibility' appears to be an important factor in the rationale for involving 'experts by experience'-it is mentioned in both reports. However, one might expect that even without their involvement, the inspection process would be both 'impartial' and 'independent'. That was, after all, the principle behind setting up independent inspection regimes in the first place (Department of Health, 2000). In any event, the report does not explain how the involvement of 'experts by experience' gives the inspection process impartiality and independence. Again, this raises some confusion about why and how the 'experts' by experience' expertise is being used. In order to be impartial, presumably they are asked to set aside any feelings or thoughts they might have about using a particular service, as this would bias their opinions. Yet, their unique, subjective experience as service users is the one thing that confers on them expert status. This particular conundrum is never addressed-are 'experts by experience' valued for their subjectivity or their objectivity?

As with the care home report, the domiciliary care evaluation includes quotations. In the latter, there are eight quotations in total; five come from inspectors, two from 'experts by experience' and one from a provider. Again, none is provided from the people who used the services provided.

An examination of the inspectors' quotations reveals a significant linguistic characteristic. When they refer to experts by experience, they drop the 'by experience' and simply refer to them as 'experts'. Arguably, this is workplace 'shorthand' coming out, but to the outside observer, to see the word 'expert' used in this unqualified way underlines the way the term has become decoupled from its 'popular' meanings. The quotation from the provider in this report starts:

Think [sic.] it made the inspection 'real' for all those involved as it was not just based on the paperwork (CSCl, 2007b, p. 3).

One can only wonder whether, inadvertently, we have been provided with an insight into what a 'normal' inspection had been like. This underlines the importance of directly engaging with and speaking to service users on service inspections.

\section{Discussion}

The intention in this paper is neither to criticise the principle of service user involvement in social care nor to suggest that service inspections should not be anything other than as rigorous as possible. However, this brief discussion of the two $\mathrm{CSCl}$ reports into the use of 'experts by experience' has highlighted three issues that would benefit from further 
consideration. The first is whether, in the context of inspections, the term 'expert by experience' is the most appropriate; the second is the lack of clarity in the role such experts play in inspections and the third is whether and how the use of 'experts by experience' actually empowers those using the services under inspection-especially those who have high support needs and who have problems with communication.

The many problems with using the word 'expert' have been discussed. However, to summarise, it would appear that the use of the term has a symbolic function, as a way of trying to address power imbalances between service users and professionals. As McLaughlin (2008) suggests, simply having experience does not make one an expert (in the accepted meaning of the word). When we talk about professional expertise, it involves the ability to develop knowledge from experience in specific contexts and then demonstrate the ability to transfer this knowledge to differing situations. As Fook et al. (2000) explain:

Expertise in this sense is context relevant, but not context dependent-it is learnt in context, but what is developed is knowledge which allows this learning to be applied successfully in new and diverse situations. Expert knowledge is, therefore, generalisable because of its contextuality. It is contextual rather than context free (Fook et al., 2000, p. 198).

In the case of 'experts by experience', expertise is entirely context-dependent. Calling someone an expert, in a colloquial sense, is relatively unproblematic as long as we want their opinions on the services they themselves received. Calling them an expert outside of this specific domain is questionable because there is currently no means of assessing and validating the generalisability of their expertise. It cannot simply be taken for granted. The title of expert-if it is to mean something that the public at large, including other service users, can understand-should not be so readily ascribed. Another reason why using the term 'expert' is inappropriate in this context is because experts who play a role in other people's lives have to face scrutiny and accountability for their decisions and their actions. It is not fair to place that degree of responsibility on people who are, essentially, ordinary members of the public. The responsibility should always remain unequivocally with the inspector. To have two sets of 'experts' on an inspection blurs the issue of whose judgement really counts. If there are any problems about, say, a poor inspection or complaints, then the inspector has his or her organisation's support. Being professional experts, they are protected by a degree of corporate responsibility. 'Experts by experience' are not-unless the support organisations who help recruit and train them take responsibility. An expert who is not accountable for the expert opinion she or he has given is a strange kind of expert. Rightly or wrongly, we live in a 'blame culture'-especially in regard to public services. As explained earlier, the role of expert therefore is a difficult one to play in contemporary society.

In their research into the use of lay assessors in inspections, Simmill-Binning et al. (2007) begin by stating that:

There is a danger of assuming that because an aspect of a process is fashionable or seems worthwhile, it must necessarily be a valuable contribution to the activity (Simmill-Binning et al., 2007, p. 1354).

Arguably, CSCI/CQC have become caught up with what is fashionable rather than what is effective. Service user involvement is an important development in social care. However, whether users of one service should be labelled 'experts by experience' when involved in the inspection of services used by others is debatable. This is particularly as the exact nature of both their expertise and role are ambiguous. For example, they have been described as 'role models' and this raises questions about aspects of inspections that really need to be made more explicit. 'Experts by experience' have also been valued for their capacity to confirm and validate inspectors' thoughts and opinions, which, again, is not something one would necessarily expect from an independent expert. However, we have also seen 'experts by experience' praised for helping to bring impartiality and independence to inspections, which, if anything, would appear contradictory to their validating role. 'Experts by experience' have also been valued for their ability to provide insights into interactions between service users and staff. Yet, the degree to which any newcomer to a situation could provide such insights is limited. This demonstrates the confusion over whether 'experts by experience' are valued for 
their specific insights into their own individual experiences or for their (untested) ability to generalise from those experiences.

Critically, an important dimension is missing from both $\mathrm{CSCl}$ reports-the views of the people who actually used the services being inspected. In an initiative that is intended to promote service user involvement, this is not only ironic, but it is a major omission. Just because certain service users feel empowered by being included in inspections as 'experts by experience' does not mean that this automatically empowers those using the services being inspected. In fact, it may even have the opposite effect.

There are parallels here with Bang's distinction between 'expert citizens' and 'everyday makers' in public service governance (Bang, 2005). 'Expert citizens' are well connected insiders whose critical potential diminishes the more they become part of the system they are challenging. Everyday makers are less involved in, but also less defined by, the system. The CSCl reports appear to be more concerned with meeting the needs of the 'experts by experience', presumably on the unevidenced assumption that this would necessarily prove advantageous to ordinary service users. At the very least, we need to see more evidence of how 'experts by experience' represent service users' perspectives and what the qualitative difference is between feedback received from an 'expert by experience' and that from an inspector or lay assessor.

Inspectors carry out a range of activities. Common methods used are: observation; discussions with staff and management; discussions with service users; reading records; consultation with relatives; and the processing of prior information provided by the service provider. Recent research carried out amongst inspectors found that they believed there was 'insufficient time available to talk properly to service users' (UNISON, 2007, p. 1). This is borne out by the $\mathrm{CSCl}$ reports, which imply, indeed state, that inspectors are more usually focused on paperwork and managerial systems than engaging with the service users.

In the spirit of empowerment, direct engagement with service users by inspectors should be a priority and, arguably, those service users with the greatest communication problems should be those whose views are most creatively, diligently and expertly sought. For example, it is recognised that effective communication is possible with people with dementia, but it requires specialised skills and knowledge (Wells, 2006). The same is the case for people with severe learning disabilities (Grove, 2000). However, unfortunately, such skills and knowledge may not be available to 'experts by experience' and it may take a long time for them to acquire, if they can at all.

Service inspectors are already able to use a range of tools in order to communicate with and involve people who use services. These include:

- $\quad$ an observational methodology for people with high dependency communication needs-Short Observational Framework for Inspection (SOFI)

- $\quad$ communication tool kit for people with learning disabilities

- $\quad$ stakeholder surveys

- $\quad$ guidance to help us make judgement about services for people with dementia

- $\quad$ using a link resident to help us engage with people in a care home (CSCI, 2007c, p. 3).

Each, potentially, offers a more appropriate and direct way of obtaining service users' views and preferences than visits from 'experts by experience'-however, well meaning or well motivated. When 'experts by experience' are used, time needs to be taken for them to be appropriately matched, prepared and skilled in order to be effective (CSCl, 2007a; 2007b). It is therefore a time-consuming exercise (a view supported by anecdotal evidence from discussions with inspectors). It is debatable whether the most effective use of hard-pressed inspectors' time is training and preparing 'experts by experience', when it is likely to prevent them from spending more time directly involved with service users. 


\section{Conclusion}

Using the term 'experts by experience' appears to be contestable in the context of service inspections. It reads almost as a courtesy title, which, in this respect, would be disempowering rather than empowering. As discussed, the use of the word 'expert' is risky for those so labelled. We no longer live in a climate of deference towards experts. These days, anyone calling themselves an expert can expect their credentials to be challenged. This potentially exposes service users' life experiences, and their understanding of their experiences, to unwarranted scrutiny as legitimation of their expertise is sought.

The way that 'experts by experience' are conceptualised and deployed is ambiguous. The employing organisation appears to be confused about their exact role and purpose. The justification for their use appears to be based on a number of, sometimes contradictory, reasons. Training up people who use one service and involving them in the inspection of services used by others raises doubts about where their true value lies and also what distinguishes them, say, from a lay assessor, much of whose value lies in bringing in an 'outsider's' view and a 'non-expert' perspective. That said, it does not mean that they might not have a value in certain service inspections. Simmill-Binning et al. (2007) state that the value of involving non-professionals might be more a matter of public perception in that it appears to make the inspection process more open and transparent. Nevertheless, they conclude that:

We do not think the [sic.] there is evidence from our own or other studies of inspections of services for adults that involving service user or lay assessors improves the quality of inspections (Simmill-Binning et al., 2007, p. 1369).

If improving the openness and transparency of inspections is an important consideration, this could be achieved by inviting people from all walks of life (including service users) to contribute to service inspections in some way. Indeed, the goals of social inclusion and 'normalisation' (in the broadest sense) might be better promoted by involving as diverse a set of perspectives as possible.

If seeking the perspective of service users is considered important, which it should be, then the most straightforward method of doing this is to have a face-to-face discussion with them. However, there are many service users with significant communication and cognitive impairments. They are entitled to have the time of inspectors trained and qualified in using specialist techniques such as those mentioned above. Failure to do so could contribute to their marginalisation and powerlessness.

The discussion began by reflecting on the contestable and 'loaded' nature of the term 'expert' in contemporary life. It is a problematic label to have attached to one and a difficult role to play. In the context of this discussion, labelling people thus and involving them in service inspections appear to be genuinely motivated by the desire to empower and which one would not want to decry. However, for the reasons set out in this paper, it mainly serves to have created a role that is hard to make sense of in terms of accepted meanings of who or what an expert is. The Care Quality Commission would do well to review both the terminological and conceptual confusion in respect of this practice.

\section{References}

Bang, H. (2005) 'Among everyday makers and expert citizens', in J. Newman, (ed.), Remaking Governance, Bristol, Policy Press, pp. 159-78.

Beck, U. (1992) Risk Society: Towards a New Modernity, London, Sage.

Beresford, P. and Campbell, J. (1994) 'Disabled people, service users, user involvement and representation', Disability \& Society, 9(3), pp. 315-25.

Brown, H. (2000) 'Challenges from service-users', in Brechin, A., Brown, H. and Eby, M. (eds), Critical Practice in Health and Social Care, London, Sage, pp. 96-116. 
Care Quality Commission (2009) Available online at http://www.cqc.org.uk/getinvolved/howweinvolvepeople/getinvolvedinoursocialcarewo rk/becomeanexpertbyexperience.cfm (accessed 3 May 2009).

Carr, S. (2004) Has Service User Participation Made a Difference to Social Care Services? Position Paper No. 3, London, Social Care Institute for Excellence.

Commission for Social Care Inspection (CSCl) (2007a) Experts by Experience in Regulatory Inspections 2006/07(Excluding Domiciliary Care) Evaluation Report, London, Commission for Social Care Inspection.

Commission for Social Care Inspection (2007b) Experts by Experience in Domiciliary Care Inspections 2006/2007 Evaluation Report, London, Commission for Social Care Inspection.

Commission for Social Care Inspection (2007c) Guidance for Inspectors: Experts by Experience, December 2007, London, Commission for Social Care Inspection.

Commission for Social Care Inspection (2009) Experts by Experience, London, Commission for Social Care Inspection.

Davis, H. and Martin, S. (eds) (2008) Public Services Inspection in the UK, London, Jessica Kingsley Publishers.

Department of Health (1994) Inspecting Social Services, LAC (94)16, London, HMSO.

Department of Health (2000) The Care Standards Act 2000, London, TSO.

Fischer, F. (2003) Reframing Public Policy; Discursive Politics and Deliberative Practices, Oxford, Oxford University Press.

Fook, J., Ryan, M. and Hawkins, L. (2000) Professional Expertise: practice theory and education for working in uncertainty, London, Whiting and Burch.

Grove, N. (2000) See What I Mean: Guidelines to Aid Understanding of Communication by People with Severe and Profound Learning Disabilities, Kidderminster, British Institute of Learning Disabilities.

Higgs, J. and Titchen, A. (2001) Practice Knowledge \& Expertise in the Health Professions, Oxford, Butterworth Heinemann.

Johnson, T. (1972) Professions and Power, London, Macmillan.

Martin, S. (2005) 'Evaluation, inspection and the improvement agenda: Contrasting fortunes in the era of evidence-based policy making', Evaluation, 11(4), pp. 496-504.

McLaughlin, H. (2008) 'What's in a name: "Client", "patient", "customer", "consumer", "expert by experience", "service user"-what's next?', The British Journal of Social Work Advance Access, 10.1093/bjsw/bcm155, 1-17.

Newman, J. (ed.) (2005) Remaking Governance: Peoples, Politics and the Public Sphere, Bristol, Policy.

Newman, J., Glendinning, C. and Hughes, M. (2008) 'Beyond modernisation? Social care and the transformation of welfare governance', Journal of Social Policy, 37(4), pp. 53157.

Powell, M. (ed.) (2008) Modernising the Welfare State: The Blair Legacy, Bristol, Policy Press.

Preston-Shoot, M. (2007) 'Whose lives and whose learning? Whose narratives and whose writing? Taking the next research and literature steps with experts by experience', Evidence and Policy, 3(3), pp. 343-59.

Seden, J. (2008) 'Innovation still needed? Service user participation in social care services and practice-led management', The Public Sector Innovation Journal, 13(1), pp. 2-9. Involvement of 'Experts by Experiences' in Inspections Page 17 of 18

Selznick, P. (1949) TVA and the Grass Roots: A Study in the Sociology of Formal Organization, Berkeley, University of California Press.

Shorter Oxford Dictionary of English, 2nd edn, revised (2005) Oxford, Oxford University Press.

Simmill-Binning, C., Clough, R. and Paylor, I. (2007) 'The use of lay assessors', British Journal of Social Work, 37(8), pp. 1353-70.

Social Policy Research Unit (SPRU) (2009) Expert Carer Programme, available online at http://www.york.ac.uk/inst/spru/research/summs/confidence.html (accessed 20 March 2009).

UNISON (2007) 'Changes in the inspection of care services and their impact on vulnerable people', Joint union briefing-UNISON in conjunction with Royal College of Nursing, Prospect and Unite. 
Wells, J. (2006) Developments in Dementia Advocacy, London, Westminster Advocacy Service for Senior Residents.

White, L. and Taket, A. (1994) 'The death of the expert', Journal of the Operational Research Society, 45(7), pp. 733-48.

Wilson, P. (2001) 'A policy analysis of the Expert Patient in the United Kingdom: Selfcare as an expression of pastoral power?', Health and Social Care in the Community, 9(3), pp. 134-42.

Wright, F. (2005) 'Lay assessors and care home inspections: Is there a future?', British Journal of Social Work, 35, pp. 1093-106. Page 18 of 18 Peter Scourfield 